\title{
Noise-Induced Cortisol Assessment among Young Motorcyclist: A field study
}

\author{
Anila Ali1,3, Roslinah Mohamad Hussain², Nazri Che Dom¹, Mujid Abdullah¹ \\ 1Department of Environmental Health and Safety, \\ 2Department of Medical LaboratoryTechnology, \\ Faculty of Health Sciences, \\ Universiti Teknologi MARA, Selangor Malaysia \\ 3Department of Environmental Management and Policy, Faculty of Engineering, \\ Balochistan University of Information Technology, Engineering and Management Sciences, \\ Quetta, Pakistan \\ anila928@yahoo.com
}

\begin{abstract}
Saliva cortisol response was investigated from the motorcycling exposure for approximately 50 minutes between low and high noise-sensitive (Weinstein Noise Sensitivity Scale) young riders (19-25 years). The results showed significant difference $(p<0.05)$ in salivary cortisol concentrations in High-Noise Sensitive group $(n=27)$. Significant gender differences were found $(p<0.05)$ among the Low-Noise sensitive group $(n=30)$, after ride. Cross-analysis between groups was significant $(p<0.05)$ for before ride cortisol levels of Low-Noise sensitive group. This study suggests that subjective noise sensitivity plays a vital role in increased cortisol level among noise sensitive riders.
\end{abstract}

Keywords: Noise; Salivary cortisol; Noise sensitivity; Motorcycle

eISSN 2398-4279 @ 2018. The Authors. Published for AMER ABRA CE-Bs by e-International Publishing House, Ltd., UK. This is an open access article under the CC BY-NC-ND license (http://creativecommons.org/licenses/by$n c-n d / 4.0)$. Peer-review under responsibility of AMER (Association of Malaysian Environment-Behaviour Researchers), ABRA (Association of Behavioural Researchers on Asians) and CE-BS (Centre for EnvironmentBehaviour Studies), Faculty of Architecture, Planning \& Surveying, Universiti Teknologi MARA, Malaysia.

DOI: https://doi.org/10.21834/ajqol.v3i13.168 


\subsection{Introduction}

The motorcycle is one of the noisiest forms of transportation where motorcyclists are exposed to noise levels ranging from 90 to $103 \mathrm{dBA}$ (Jordan, Hetherington, Woodside, \& Harvey, 2004). Noise is regarded as an environmental stressor, activates the hypothalamus-pituitaryadrenal (HPA) axis which stimulates the glucocorticoid stress hormone known as cortisol (Marques, Silverman, \& Sternberg, 2010). It provides beneficial energy to body but the prolonged secretion becomes harmful, resulting in risk factors for diseases which under chronic nature involves a long-lasting activation (Lefèvre et al., 2017). Saliva cortisol has been validated as plasma-free cortisol concentration, presenting a biomarker of a stress reaction to noise exposure. Collection of saliva sample is feasible, noninvasive, standardized and easy to handle in field studies related to noise research (Bigert et al., 2005). Noise sensitivity (NS), as a predictor and moderator of health outcomes and well-being, has gained interest in the past years. Noise sensitivity is a personal trait encompassing internal factors (e.g., physiological, psychology, attitudinal) that increase an individual's susceptibility to the effects of noise (R. F. S. Job, 1999). Individual categorized as high-noise sensitive tends to get more affected by the exposed noise than the individuals who are insensitive, merely because of coping abilities with noise (Shepherd, Welch, Dirks, \& Mathews, 2010). Previous studies reported lower threshold for physiological stress reactivity among NS individual (Waye et al., 2002).Motorcyclists psychological health related studies are scarce, while research on rider's noise-induced cortisol arousals has not been investigated previously. Therefore, this study aimed to determine the effects of noise exposed during motorcycle ride on differential effects on their cortisol concentration and to evaluate the influence of noise sensitivity on the cortisol reactivity.

\subsection{Methodology}

\subsection{Study participants}

A cross-sectional study based on survey and field experiment. Participants were collected through simple random sampling technique across different faculties at Universiti Teknologi Mara, Kampus Puncak Alam Malaysia, representing from all over Malaysia (Masuri, Dahlan, Danis, \& Isa, 2017); (Masuri, Isa, \& Tahir, 2012). To be eligible for the study, participants had to be: (i) between 19 to 25 years old (Norfazila, Mustaffa, \& Ghazali, 2017); (ii) nonsmoker; (iii) absence of chronic diseases; (iv) riding motorcycle as primary means of transportation; and $(v)$ helmet-riding behavior. A set of structured questionnaires consisted of study information sheet, respondent's demographic questionnaire and Weinstein Noise Sensitivity Scale (WNSS) were distributed among 356 motorcyclists, while 330 returned the questionnaire. A total of 301 respondents endorsed written consent form of participation before a commencement of the study. Later, based on WNSS score, respondents participated in the field experiment. Study procedure and design were approved by Faculty's (Health Sciences) Internal Ethical Committee, Universiti Teknologi Mara. 


\subsection{Study Instruments}

\subsubsection{Demographic Information}

The participant's demographic data was obtained through a self-reported questionnaire, which consisted of data related to age, gender, years of motorcycling experience (as a primary mode of transportation), faculty, the semester of enrollment, motorcycle license, usage of the helmet, smoking habit and presence of any chronic diseases.

\subsubsection{Weinstein Noise Sensitivity Scale}

The Weinstein Noise Sensitivity Scale (WNSS) consisted of 21 -items on six-point Likerttype scale, ranging from "disagree strongly" to "agree strongly." The scores ranged between 21 to 126, i.e., minimum and maximum respectively. Previous researchers, both from the field and experimental studies have tested satisfactory psychometric properties, predictive validity and internal consistency of the questionnaire, which ranged from 0.84 to 0.87 (Kuder-Richardson reliability)(Weinstein, 1978).

\subsubsection{Saliva collection instruction}

Instructions were categorized mainly into the night before, on the day, one hour before and 10 minutes before sample collection, to avoid contamination in the oral cavity, to control pH level and increased levels of cortisol concentrations in saliva (Elbüken et al., 2014).

\subsubsection{Saliva collection procedure}

Participants were instructed to tilt their head forward for increased secretion of saliva into the oral cavity and transfer directly into a $2 \mathrm{ml}$ saliva collection polypropylene vial as passive drool method. Contaminated samples with blood were discarded and repeated with 10 minutes break after mouthwash with cold water. Samples were stored within 30 minutes of collection at $-80^{\circ} \mathrm{C}$ (Elbüken et al., 2014).

\subsection{Study Procedure}

Figure 1 illustrates the study procedure, where for exploring the differences in salivary cortisol concentration due to motorcycling exposure, respondents from only the H-NS group and LNS group were recruited for the field experiment. On the field-experiment day, participants bought their motorbike to the testing site where saliva instructions checklist was marked, relaxed for 10 minutes and obtained saliva as "before ride" sample. Participants commenced from destination D1 (UiTM, Puncak Alam, Faculty of Education bus stop) to D2 (Uitm Perdana) and returned to D1 (45 minutes), to ensure the maximum arousal of cortisol concentration (Sylvie Hebert \& Lupien, 2009). Immediately, upon the arrival at D1 via D2, saliva collected as "after ride" sample. Saliva samples were stored in aliquots to avoid repeated freeze thaw. Cortisol analysis was performed by Immunoassay (EIA) technique with the High-sensitivity human salivary cortisol-ELISA (enzyme-linked immunosorbent assay) kit (Salimmetrics, State College, PA, USA), followed manufacturer's instructions (Salimetrics, 2014) at the optical density of $450 \mathrm{~nm}$. The coefficients of variation (CV) were calculated from the means of triplicated saliva assay, expressed in $\mu \mathrm{g} / \mathrm{dL}$. The intra and inter assay CV's 
were less than $5 \%$ and $15 \%$ respectively.

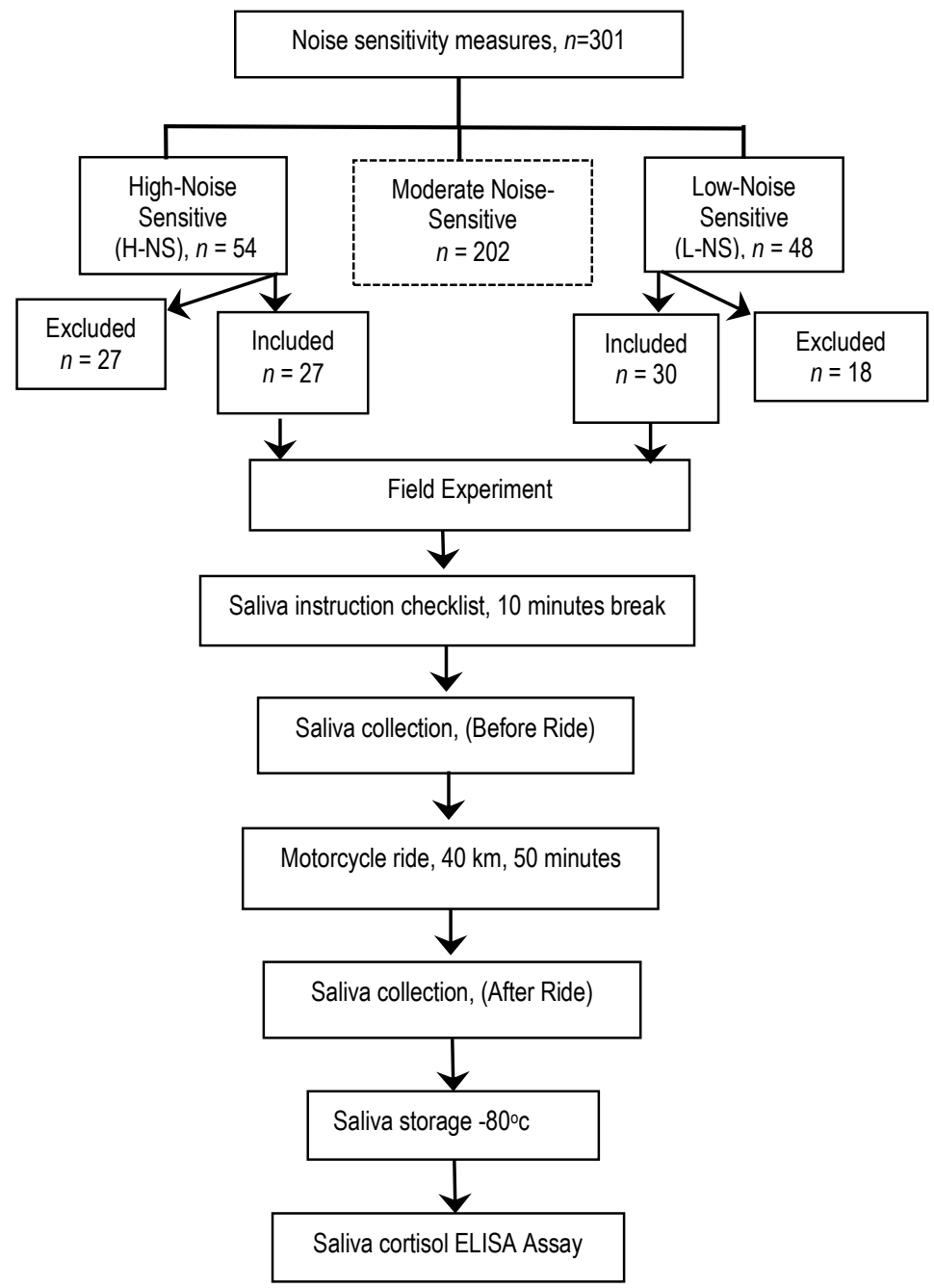

Figure 1: Study Procedure: Participants distribution from noise-sensitivity to field experiment, process of salivary cortisol collection and cortisol measurements (ELISA-assay)

\subsection{Statistical analysis}

Data distribution was found not normally distributed through Shapiro-Wilk test. To evaluate the differences between before and after ride cortisol concentration in L-NS and H-NS, Wilcoxon Sign ranked test was conducted, whereas, gender differences of L-NS and H-NS 
groups cortisol concentration before and after the motorcycle ride was determined through two samples independent tests (Mann-Whitney U-test). Cross-analysis were also conducted between the two groups before and after ride cortisol concentrations through Welch t-test. Bar charts and box and whiskers were plotted to demonstrate the mean and median differences of saliva cortisol concentration for both the groups before and after motorcycle ride. An alpha level of 0.05 was used for subsequent analysis through Statistical Package for Social Sciences, IBM SPSS (Version 22 Inc., Chicago, IL).

\subsection{Results and Discussion}

\subsection{Noise sensitivity}

The estimated value of coefficient of reliability for WNSS items $(n=301)$ was statistically reliable, $\alpha_{c}=0.776$. Noise sensitivity (NS) groups constituted into low-noise sensitive (L-NS) $\left(W_{N S S} S_{\text {(mean) }}=65.72 \pm S D, 4.36 ; n=48\right), \quad$ moderate-noise sensitive $(M-N S) \quad\left(W N S S_{\text {(mean) }}=\right.$ $82.49 \pm S D, 6.7 ; n=202)$ and high-noise sensitive (H-NS) (WNSS (mean) $=101.8 \pm S D, 5.31 ; n=54)$. For the field experiment, 27 from H-NS group and 30 from L-NS group participated.

\subsection{Descriptive profile of participants of the field experiment}

Table 1 presents the demographic profile of the participants $(n=57)$ recruited in the field experiment. Participation was dominated by male riders $(n=40,70 \%)$. Participants mean age was $22.02(S D=1.172)$. Participation of motorcyclists ranged from semester 1 till 8 , while driving age ranged from 1 to 12 years, with mean driving age of $6.8(S D=2.747)$. The L-NS group consisted of $24(80 \%)$ males. Participants mean age was $21.90(S D=1.34)$. H-NS group constituted $16(59 \%)$ males. Participants mean age was $22.95(S D=0.95)$.

Table 1: Demographic profile of motorcyclists who participated in the field experiment

\begin{tabular}{|c|c|c|c|c|}
\hline & Variables & $\begin{array}{l}\text { Total } \\
N=57\end{array}$ & $\begin{array}{l}\text { L-NS group } \\
n=30\end{array}$ & $\begin{array}{l}\text { H-NS group } \\
n=27\end{array}$ \\
\hline \multirow{5}{*}{ (M/F) } & Gender & $40 / 17$ & $24 / 6$ & $16 / 11$ \\
\hline & & $M+S D$ & $M+S D$, range & $M+S D$ \\
\hline & Age, (yrs.) & $\begin{array}{c}22.02 \pm 1.172,19- \\
25\end{array}$ & $21.90 \pm 1.34,20-25$ & $22.15 \pm .95,19-24$ \\
\hline & Semester & $4.77 \pm 1.40,1-8$ & $4.56 \pm 1.43,1-7$ & $5.0 \pm 1.3,2-8$ \\
\hline & Driving age & $6.807+2.747,1-12$ & $7.07+3.107,1-12$ & $6.52+2.31,2-10$ \\
\hline
\end{tabular}

\subsection{Cortisol concentration analysis}

L-NS group mean concentration of cortisol before and after motorcycle ride was $0.17 \pm 0.11$ $\mu \mathrm{g} / \mathrm{dL}$ and $0.15 \pm 0.06 \mu \mathrm{g} / \mathrm{dL}$ respectively. Results among $\mathrm{L}-\mathrm{NS}$ riders indicated no significant difference between before and after ride cortisol concentration, $\underline{z}=-1.502, p=0.133$. Results 
showed that L-NS had no effect on their cortisol concentrations after motorcycle ride. The median $(0.148 \mu \mathrm{g} / \mathrm{dL})$ cortisol concentration before ride among L-NS group is shown in boxplot (Figure $2 \mathrm{~A})$ indicates slightly higher than after ride $(0.135 \mu \mathrm{g} / \mathrm{dL})$. It was also observed that cortisol concentration interquartile range before ride $(0.102-0.253 \mu \mathrm{g} / \mathrm{dL})$ was higher than after ride $(0.106-0.186 \mu \mathrm{g} / \mathrm{dL})$.



Figure 2: Salivary cortisol concentration differences between "before" and "after" ride: (A) Low-Noise Sensitive group (B) High-Noise Sensitive Group. Note: $\left({ }^{*}\right)$ p-value $<0.05$ between before ride and after ride.

H-NS group mean concentration of cortisol before and after motorcycle ride was $0.12 \pm 0.08 \mu \mathrm{g} / \mathrm{dL}$ and $0.16 \pm 0.1 \mu \mathrm{g} / \mathrm{dL}$ respectively. Statistical analysis revealed significant increase in H-NS group cortisol levels after the motorcycle ride, $\underline{z}=-2.667, p=0.008$. Box-plot (Figure 2B) illustrates $\mathrm{H}-\mathrm{NS}$ group cortisol concentration levels comparison between before and after motorcycle ride. It shows significantly higher median $(0.155 \mu \mathrm{g} / \mathrm{dL})$ concentration of cortisol levels after riding compared to before ride $(0.084 \mu \mathrm{g} / \mathrm{dL})$. The cortisol concentration interquartile range after ride $(0.078-0.228 \mu \mathrm{g} / \mathrm{dL})$ was higher than before motorcycle ride $(0.061-0.143 \mu \mathrm{g} / \mathrm{dL})$.

\subsubsection{Gender differences}

Genders effects on cortisol concentrations in L-NS and H-NS group were analysed for both before and after motorcycling exposure. For the L-NS group, no significant difference was found in before motorcycle ride, $U=56, p=0.407, r=0$. However, mean ranks for the female riders showed higher ranks (18.17) compared to male riders (14.83). Figure $3 \mathrm{~A}$ presents overlapping error bars indicating no noticeable difference between male and female cortisol concentrations before motorcycle ride in the L-NS group. 


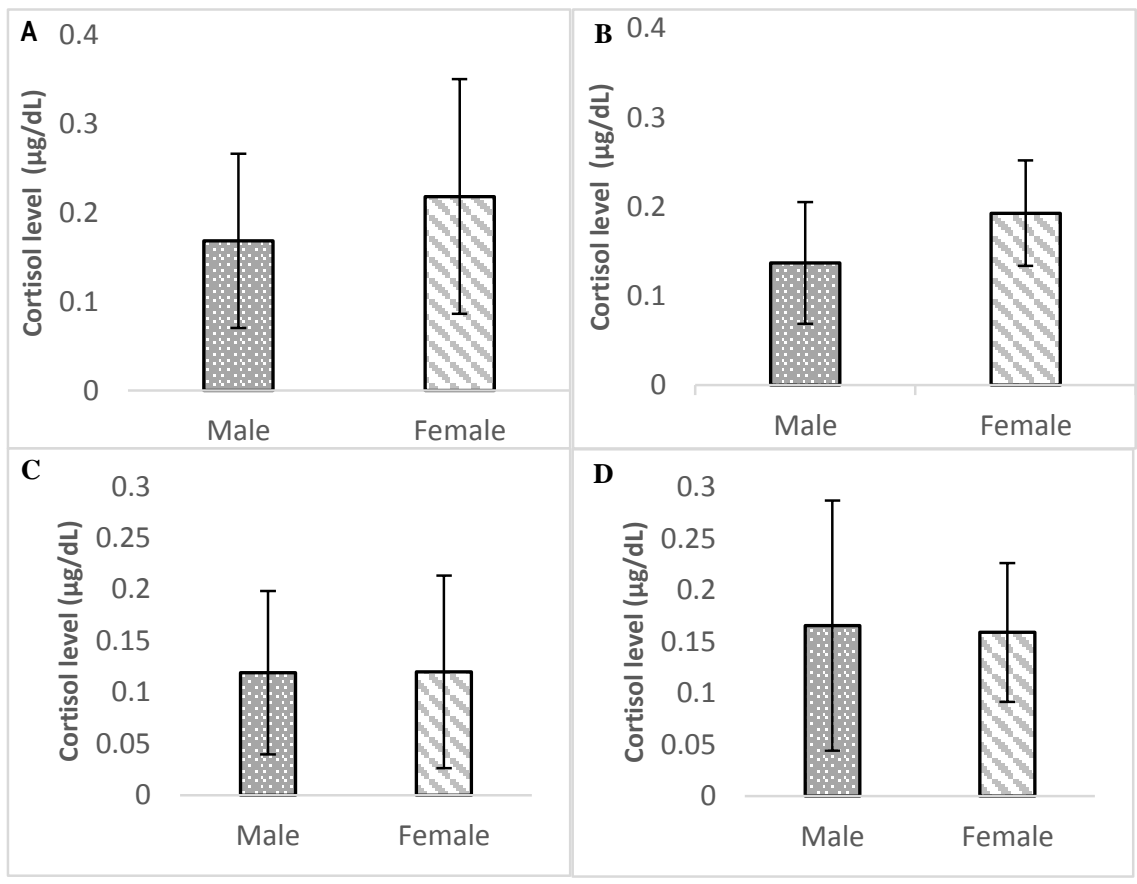

Figure 3: Gender difference in cortisol concentration: $(A)$ "Before ride" among the Low-Noise Sensitive group; (B) "After ride" among the Low-Noise Sensitive group; (C) "Before ride" among the High-Noise Sensitive group; (D)"After ride" among the High-Noise Sensitive group. Note: ( $\left.{ }^{*}\right)$ p-value $<0.05$ between males and females.

Moreover, after ride cortisol concentration was significantly higher among female riders (Mranks $=22.08$ ) than male participants (Mranks $=13.85$ ), $U=32.50, p=0.040, r=0.04$.) in the LNS group. Figure 3B presents less overlapping error bar indicating significantly increased cortisol concentration among female rider's after motorcycle ride in the L-NS group. Results indicated that female riders from L-NS group had increased cortisol leve. H-NS group showed no significant gender difference in cortisol concentration before $(U=88, p=1.00, r=0.159)$ and after motorcycle ride $(U=83.00, p=0.805, r=0.394)$. Before ride, both genders had equal mean ranks (14) as shown in Figure $3 \mathrm{C}$ and $3 \mathrm{D}$ with overlapping error bar, whereas, after ride females had slightly higher value (14.45) than males (13.69).

\subsubsection{Cross-analysis among groups}

The participant's cortisol concentration before and after motorcycle ride were cross analysed between the two studied groups (L-NS and H-NS) through Welch t-test. Cortisol concentration before ride between L-NS $(M=0.17, S D=0.1049)$ and $H-N S$ groups $(M=0.119$, $S D=0.0853$ ) was significant, $F(1,54.47)=5.446, p=0.023$. Cross-analysis for before 
motorcycle ride among groups is shown in box-plot (Figure 4A) which indicates that L-NS riders had higher median cortisol concentration $(0.148 \mu \mathrm{g} / \mathrm{dL})$ compared to $\mathrm{H}-\mathrm{NS}$ riders $(0.084 \mu \mathrm{g} / \mathrm{dL})$ with higher interquartile range for before ride of L-NS $(0.102-0.253 \mu \mathrm{g} / \mathrm{dL})$ compared to the H-NS $(0.061-0.143 \mu \mathrm{g} / \mathrm{dL})$. Cortisol concentration between L-NS $(M=0.148$, $S D=0.069)$ and $H-N S$ group $(M=0.163, S D=0.1013)$ after motorcycle ride was found nonsignificant, $F(1,45.340)=0.400, p=0.530$. It is shown in box-plot (Figure 4B) which indicates that H-NS riders had higher median cortisol concentration $(0.155 \mu \mathrm{g} / \mathrm{dL})$ than L-NS riders $(0.135 \mu \mathrm{g} / \mathrm{dL})$ with higher interquartile range $0.078-0.228 \mu \mathrm{g} / \mathrm{dL}$ compared to L-HS group $(0.106-0.186 \mu \mathrm{g} / \mathrm{dL})$.

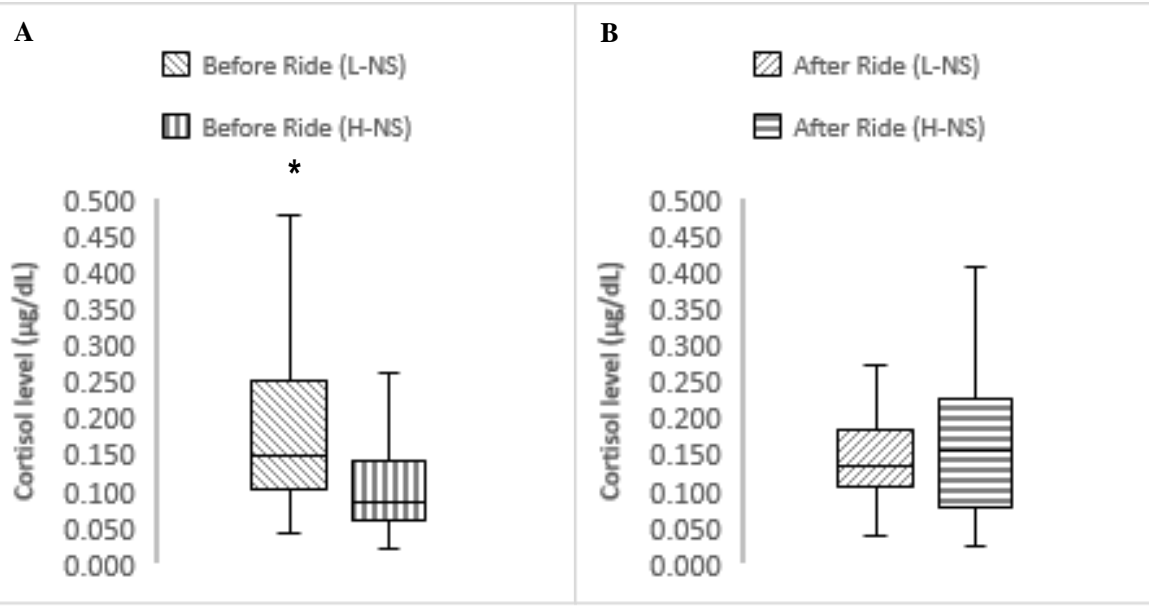

Figure 4: Cross-analysis among groups between before ride and after ride cortisol differences: (A) Cortisol concentration difference "Before ride" between Low and High-Noise Sensitive group; (B) Cortisol concentration difference "After ride" between Low and High-Noise Sensitive. Note: $\left(^{*}\right) p$-value $<0.05$.

\subsection{Discussion}

This study carried out a noise sensitivity assessment of young motorcyclists $(n=301)$ which revealed that a majority (66.7\%) of the population encompasses the moderate level of noise sensitivity while minor percentage were at the two extreme points of the noise sensitivity scale. Previous studies reported similar results on different populations by concluding that minor population exhibits higher noise-sensitivity traits with greater susceptibility of health risk associated with it (Kishikawa et al., 2006; Oiamo, Luginaah, \& Baxter, 2015).

On account of average motorcycling exposure, motorcycle riders may experience noise levels above $90 \mathrm{dBA}$, (Chris Jordan, Oliver Hetherington, Alan Woodside, 2004), which is sufficient for activation of HPA axis and release of cortisol for combating the acute stressor. For precise investigation of noise-induced cortisol reactivity, NS was assessed and recruited from low and high NS group for possible comparison in their stress response. The focus on 
NS investigation on public health research is rare, but the evidence suggests that NS may be a health risk factor unto itself (Fyhri \& Klæboe, 2009) During the day, cortisol tends to decline naturally, particularly in the morning. Therefore, differential effects of noise could be explained either regarding an evaluated level of cortisol from before to after riding exposure or regarding decline cortisol level, reflecting the extent of how stressful the motorcycling exposure has influenced on HPA axis. The findings of the current study revealed cortisol level to be positively associated with the $h$-ns group after the riding exposure $(p=0.008)$.

Waye's (2002) exposed respondents to low-frequency noise and determined its relation to cortisol (salivary) and performance and reported significant association between noise and increased cortical secretion with decreased performance in battery test among H-NS (Waye et al., 2002). Motorcyclists with H-NS may also experience impaired cognitive functioning during a commute and may behold risk factor to road accidents (Ali et al., 2016), which requires further investigation. Another study reported no significant relation between cortisol arousal with noise among NS participants but stated impaired cognitive performance (Ljungberg \& Neely, 2007).

Another laboratory study exposed the respondents to noise level up to $75 \mathrm{~dB}$ for 20 minutes, and saliva samples were collected before and after and reported the significant increase in cortisol levels from before to after test performance $(p=0.01)$ (Wagner et al., 2010), despite the small sample and NS was not determined. Similarly, in another study significant increase in cortisol concentration were reported after artificially induced doseresponse noise exposure in the laboratory setting, which peaked after about 30 minutes and then gradually dropped with a termination of noise (Sylvie Hebert \& Lupien, 2009)

The above-cited studies did not provide any gender analysis in their studies. This study did not show any significant differences in gender cortisol concentration reactivity among $\mathrm{H}$ NS riders $(p=0.407)$. In contrast, L-NS female riders showed significantly $(p=0.04)$ higher cortisol concentration after the ride. Cross-analysis between categorized groups showed that L-NS riders tend to have significantly higher cortisol concentration before ride $(p=0.023)$ from $\mathrm{H}-\mathrm{NS}$ riders. These results increase the credibility of the analysis because the young motorcyclist in the H-NS had significantly increased cortisol level after motorcycle exposure $(p=0.008)$ reflecting the acute stress response, while L-NS higher cortisol before ride needs to be investigated for further explanation. The limitation of the study was that other individual variables were not investigated such as sleeping patterns, hearing status, and personality traits. However, the strength is the sample size presenting both groups as H-NS and L-NS. Salivary cortisol samples were handled with care, and ELISA assay was conducted in triplicate for each sample. Furthermore, the results that we found reflects the acute noiseinduced stress response rather than from long-term exposure to stress.

\subsection{Conclusion}

In conclusion, the results of the study reveal that the exposure of motorcycle to wind noise caused alterations in salivary cortisol concentration among subjects categorized as highnoise sensitive. To our knowledge, this study is the first to demonstrate the salivary cortisol reactivity based on real-field exposure. Thus, this study provides the baseline for future 
research.

\section{Acknowledgement}

The study was supported by CORE Shah Alam and Faculty of Health Sciences, UiTM Selangor, Puncak Alam Campus under Award Numbers 600-RMI/DANA 5/3 LESTARI (3/2015) and 600-RMI/MYRA 5/3 LESTARI (0016/2016).

\section{References}

Ali, A., Karuppannan, S., Hussain, R. M., Rajan, S., Abdullah, M., Ikhwan, R., \& Chinna, K. (2016). Epidemiological root cause analysis of noise and physio - psycho impacts related to motorcycle road accidents. Journal of Scientific Research and Development, 3(5), 150-156.

Bigert, C., Bluhm, G., \& Theorell, T. (2005). Saliva cortisol - a new approach in noise research to study stress effects. Int. J. Hyg. Environ.-Health, 208, 227-230.

Chris Jordan, Oliver Hetherington, Alan Woodside, H. H. (2004). Noise induced hearing loss in occupational motorcyclists. Journal of Environmental Health Research, 3.

Elbüken, G., Köse, K., Karaca, Z., Tanrıverdi, F., Ünlühizarcı, K., Zararsız, G., \& Keleştimur, F. (2014). Comparison of Electrochemiluminescence and Enzyme Immunoassay Methods for the Measurement of Salivary Cortisol Tükrük Kortizolü Ölçümünde Elektrokemilüminesan ve Enzimimmünoassay Yöntemlerinin Karşılaştıııması, (15), 111-115.

Fyhri, A., \& Klæboe, R. (2009). Road traffic noise, sensitivity, annoyance and self-reported health-A structural equation model exercise. Environment International, 35(1), 91-97.

Job, R. F. S. (1999). Noise sensitivity as a factor influencing human reaction to noise. Noise \& Health, 1, 57-68.

Jordan, C., Hetherington, O., Woodside, A., \& Harvey, H. (2004). Noise induced hearing loss in occupational motorcyclists. Journal of Environmental Health Research, 3(2), 70-77.

Kishikawa, H., Matsui, T., Uchiyama, I., Miyakawa, M., Hiramatsu, K., \& Stansfeld, S. a. (2006). The development of Weinstein's noise sensitivity scale. Noise \& Health, 8(33), 154-160.

Lefèvre, M., Carlier, M., Champelovier, P., Lambert, J., Laumon, B., Evrard, A., ... Bernard, U. C. (2017). Effects of aircraft noise exposure on saliva cortisol near airports in France. Occup Environ Med, 1-8.

Ljungberg, J., \& Neely, G. (2007). Stress, subjective experience and cognitive performance during exposure to noise and vibration. Journal of Environmental Psychology, 27, 44-54.

Marques, A. H., Silverman, M. N., \& Sternberg, E. M. (2010). Evaluation of Stress Systems by Applying Noninvasive Methodologies: Measurements of Neuroimmune Biomarkers in the Sweat, Heart Rate Variability and Salivary Cortisol. NeurolmmunoModulation, 17, 205-208.

Masuri, M. G., Dahlan, A., Danis, A., \& Isa, K. A. (2017). Attitude towards Safe Driving Scale ( ASDS-46 ) as a Future Predictor in Determining a Young Adult Quality Of Life : Part II. Environment-Behaviour Proceedings Journal, 2(5), 363.

Masuri, M. G., Isa, K. A. M., \& Tahir, M. P. M. (2012). Children, Youth and Road Environment: Road Traffic Accident. 
Procedia - Social and Behavioral Sciences, 38(December 2010), 213-218.

Norfazila, D., Mustaffa, A., \& Ghazali, M. (2017). Speeding Intention among Young Urban Drivers. Asian Journal of Behavioural Studies, AjBeS, 2(7), 43-51.

Oiamo, T. H., Luginaah, I. N., \& Baxter, J. (2015). Cumulative effects of noise and odour annoyances on environmental and health related quality of life. Social Science \& Medicine, 146, 191-203.

Salimetrics. (2014). High Sensitivity salivary cortisol. Retrieved from https://www.salimetrics.com/assets/documents/1-3002.pdf

Shepherd, D., Welch, D., Dirks, K. N., \& Mathews, R. (2010). Exploring the Relationship between Noise Sensitivity, Annoyance and Health-Related Quality of Life in a Sample of Adults Exposed to Environmental Noise. International Journal of Environmental Research and Public Health, 7, 3579-3594.

Stokholm, Z. A., Hansen, A. M., Grynderup, M. B., Peter, J., Lodberg, K., Winther, T., Kolstad, H. A. (2014). ScienceDirect Recent and long-term occupational noise exposure and salivary cortisol level. Psychoneuroendocrinology, 39, 21-32.

Sylvie Hebert, \& Lupien, S. J. (2009). Salivary cortisol levels, subjective stress, and tinnitus intensity in tinnitus sufferers during noise exposure in the laboratory. Int. J. Hyg. Environ.-Health, 212, 37-44.

Wagner, J., Cik, M., Marth, E., Santner, B. I., Gallasch, E., Lackner, A., \& Raggam, R. B. (2010). Feasibility of testing three salivary stress biomarkers in relation to naturalistic traffic noise exposure. International $\mathrm{Jl}$ of Hygiene and Environ Health, 213(2), 153-155. http://doi.org/10.1016/j.jijheh.2009.08.004

Waye, K. P., Bengtsson, J., Rylander, R., Hucklebridge, F., Evans, P., \& Clow, A. (2002). Low-frequency noise enhances cortisol among noise sensitive subjects during work performance. Life Sciences, 70, 745-758.

Weinstein, N. D. (1978). Individual differences in reactions to noise: a longitudinal study in a college dormitory. The Journal of Applied Psychology, 63(4), 458-466 